УДК 327.5

Александр ШУМИЛИН

Инна ШУМИЛИНА

\title{
СИРИЯ ПОСЛЕ ИГИЛ: ОСОБЕННОСТИ ПОДХОДА США И ЕВРОСОЮЗА
}

\begin{abstract}
Аннотация. На протяжении 2018 г. команда Дональда Трампа заметно корректировала свою стратегию в отношении сирийского кризиса: от объявленного в апреле месяце намерения “вывести американские войска из Сирии” (после нанесения поражения террористической группировке "Исламское государство"1) до заявления о готовности США делать ставку на военную силу и дипломатию с целью добиться задачи, сформулированной в качестве первоочередной, - ликвидации военного присутствия Ирана в этой арабской стране. Однако, попытка Вашингтона привлечь Москву к реализации своей антииранской линии в Сирии провалилась. Страны ЕС также не готовы полностью согласиться с антииранской стратегией Трампа в Сирии и в ближневосточном регионе в целом. В данной статье авторы рассматривают особенности взаимоотношений между США и ЕС по сирийской проблеме.

Ключевые слова: США, Евросоюз, Сирия, Иран, Россия, компромисс, джихадисты, ИГИЛ, Дональд Трамп, Владимир Путин.

4 апреля 2018 г. Дональд Трамп заявил, что террористическая группировка Исламское государство “практически полностью” разгромлена (close to 100 percent) и он, как верховный главнокомандующий, даёт указание Пентагону подготовиться к выводу войск из Сирии [De Young K., Harris S., April 4. 2018]. Эта позиция президента США вызвала недоумение и озабоченность как в военном и политическом истеблишменте в Вашингтоне, так и среди руководителей ведущих стран Евросоюза. Во-первых, для полного разгрома боевиков ИГ ещё требовались серьёзные усилия [De Young K., Harris S., April 4. 2018]. Заметим, что даже в сентябре месяце 2018 г. эти террористы продолжали контролировать существенную часть территории на юго-востоке Сирии, а также сохраняли влияние в южных районах этой страны. Поспешный, по мнению несогласных с решением Трампа, вывод американских войск может послужить сигналом для подразделений других стран международной коалиции (всего эта структура насчитывает 74 государства), которые могут последовать примеру США, в результате чего может возникнуть вакуум безопасности на
\end{abstract}

${ }^{1}$ ИГ - группировка, запрещённая в России.

(C) Шумилин Александр Иванович - доктор политических наук, главный научный сотрудник отдела европейской безопасности Института Европы РАН. Aдpec: 125009, Россия, Москва, Моховая ул., д. 11, стр. 3. E-mail: mideast@bk.ru

Шумилина Инна Викторовна - кандидат политических наук, старший научный сотрудник Института США и Канады РАН. Адрес: 121069, Россия, Москва, Хлебный пер., д. 2/3. E-mail: innashu@mail.ru

DOI: http://dx.doi.org/10.15211/soveurope620187381 
освобождённых от ИГ и неподконтрольных Асаду территориях. Кроме того, лишенные огневой поддержки коалиции с воздуха курды и сирийские повстанцы, непосредственно контролирующие эти территории, могут стать объектами атак как со стороны остатков джихадистских группировок, так и со стороны вооруженных сил Башара Асада и Ирана при поддержке ВКС России. Наконец, несогласные с Трампом в США и Европе утверждали, что самоустранение международной коалиции, несомненно, сработает на укрепление позиций режима Б. Асада, облегчит ему задачу восстановления контроля над всей территорией страны, что, по их мнению, не решит сирийскую проблему, а только усугубит её. Долгосрочное решение критики Трампа видели и видят в завершении процесса политического транзита власти в Сирии под эгидой $\mathrm{OOH}$.

Постепенно менять свое отношение к проблеме “вывода из/сохранения в" Сирии американских подразделений Д. Трамп начал под воздействием ряда факторов. Прежде всего западные политики и спецслужбы поспешили возложить ответственность за применение химоружия 8 апреля 2018 г. на Башара Асада: глава Белого дома назвал сирийского президента “животным”, пообещав, что тот “заплатит высокую цену” за содеянное [Watkins E., April 9, 2018]. Ранее провозглашенная Трампом готовность вывести американские войска из Сирии выглядела уже нелогичной в данном контексте. Но ещё основательнее повлияли на президента США факторы, связанные с его внутриполитическими расчётами, а также позиция, занятая лидерами крупнейших стран Евросоюза (Великобритании, Германии, Франции).

\section{Трамп: проблема Сирии как “отголосок” проблемы Ирана}

Именно такой расстановкой акцентов (“Проблема Ирана важнее проблемы Сирии”) можно объяснить анонсирование Джеймсом Джеффри, назначенным в середине августа 2018 г. спецпредставителем Государственного департамента по сирийской проблеме, того, что в американской прессе начали называть “новой стратегией США по Сирии". Так, 6 сентября этого же года газета The Washington Post приводит следующие слова Дж. Джеффри: “Новая политика по Сирии сводится к тому, что мы уже не выводим свои подразделения из этой страны до конца текущего года... Американские военные останутся, там пока Сирию не покинут иранские подразделения и будет нанесено окончательное поражение "Исламскому государству"... Это означает, что мы не торопимся: президент санкционировал более активный подход к проблеме". Речь идёт, суммирует автор статьи Карен ДеЯнг, специалист по вопросам национальной безопасности, о новом "натиске" США по сирийскому вопросу как на военном, так и на дипломатическом поприще [DeYoung K., September 6, 2018]. Сотрудники Белого дома, опрошенные аналитиком К. ДеЯнг пояснили, что новую линию поведения в сирийском конфликте американский президент одобрил после того, как российская сторона, мол, подтвердила свою “неспособность и нежелание" убедить Иран вывести его военные формирования из Сирии [DeYoung K., September 6, 2018]. Дело в том, что, несмотря на ракетные удары США и их европейских союзников по объектам вооружённых сил Сирии в апреле 2018 г., которые сопровождались жесткими словесными угрозами со стороны Трампа в адрес сирийского президента Б. Асада, уже тогда было достаточно оснований утверждать, что сирийская проблема остается для американского президента вторичной и во многом производной от более значимой для США проблемы Ирана. Ярким подтверждением этому стали последующие события, в частности, заявление 
Трампа от 8 мая 2018 г. о выходе США из международной “ядерной сделки” с Ираном от 2015 г. (Совместный всеобъемлющий план действий - СВПД/JCPOA). В результате этого шага противодействие “экспансионистской политике Ирана" было провозглашено краеугольным камнем ближневосточной стратегии Белого дома. На этой антииранской основе Д. Трамп пытался достичь компромисса и с российским президентом Владимиром Путиным на их встрече в Хельсинки 16 июля 2018 г. Формула такого компромисса, судя по всему, выглядела так: США (временно) соглашаются с сохранением в Дамаске Башара Асада, а Россия - содействует сдерживанию амбищий и сокращению масштабов присутствия Ирана в Сирии; роль же Европы сводится к участию в обеспечении гуманитарных миссий.

Впрочем, ещё накануне саммита в Хельсинки - в ходе активных контактов с иранскими партнерами - глава МИД РФ Сергей Лавров заявил о нереалистичности компромисса, построенного на антииранской основе. 4 июля 2018 г. на прессконференции он раскритиковал требование США к Ирану полностью вывести его войска из Сирии, пояснив, что Иран не уйдет из этой страны и не перестанет играть свою роль в регионе. "Понятно, что это абсолютно нереалистично и что решать проблемы региона без участия ключевых его стран, в том числе Ирана, Саудовской Аравии, Иордании, Египта и многих других, не получится", - подчеркнул Лавров [Лавров считает уход Ирана из Сирии нереалистичным, 2018]. Позднее эту позицию подтвердил и президент РФ Владимир Путин во время встречи с Джоном Болтоном, помощником президента США по нацбезопасности: по словам Болтона, Путин сказал ему, что Москва не в состоянии принудить Иран покинуть Сирию, хотя цели России и Ирана в этой стране “не полностью совпадают” [Williams D., August 22, 2018].

Провал намерения США взаимодействовать с Россией в Сирии на антииранской основе привёл к частичной корректировке подхода команды Трампа к сирийской проблеме: помимо уже упомянутого отказа от вывода американских военнослужащих из Сирии “новая стратегия" возвращает такую базовую установку времен президентства Барака Обамы, как уход Башара Асада с поста президента в результате политического транзита [DeYoung K., September 6, 2018]. Антииранская же доминанта остается главным элементом подхода Белого дома к сирийской проблеме.

Следует подчеркнуть, что ставку на “антииранизм” (демонизацию Ирана) Трамп успешно эксплуатировал еще в ходе своей избирательной кампании на протяжении 2016 года. Она оказалась достаточно эффективной и во внутриполитическом аспекте: отталкиваясь от критики политики Обамы по Ирану (“ядерная сделка" 2015 г.) и Сирии (“химическая сделка" вместо ударов по войскам Асада в 2013 г.), произраильские и проарабские (в основном суннитских монархий Персидского залива) лоббистские структуры в США активно мобилизовывали своих сторонников в поддержку Трампа. Эти два элемента, составившие основу ближневосточной политики команды 45-го президента США, выразились в следующих действиях: в а) провозглашении Трампом намерения выйти из СВПД, за которым последовали реальные шаги в мае 2018 г.; и в б) применении силы (ракетные удары) против сил Асада в случае использования последним химического оружия.

По разным опросам, от половины до двух третей американцев с правом голоса устойчиво поддерживали удары по позициям армии Асада в апреле 2017 и 2018 гг. (по данным Gallup, 50\%, а по данным Rasmussen - свыше 62\% [Reinhart R., April 24, 2018]. При этом на протяжении 2017 и 2018 гг. опросы фиксировали нежелание/отказ большинства американцев ввязываться в боевые действия (наземные) как Современная Европа, 2018, №6 
в Сирии, так и особенно против Ирана, ограничиваясь ракетными ударами в случае необходимости. Опросы фиксируют существенное преобладание таких настроений как на массовом уровне, так и их отражение в политическом классе независимо от партийной принадлежности: опубликованный в начале января 2018 г. опрос компанией J. Wallin Opinion Research показал, что против втягивания в наземные операции, но применение ограниченных военных мер высказываются $78 \%$ демократов, $64,5 \%$ республиканцев и 68,8\% независимых политических активистов. При этом $86,4 \%$ опрошенных считают, что в качестве “последнего аргумента" может и должна использоваться сила [Garden J., January 9, 2018]. Согласно данным Rasmussen Reports, в сентябре 2018 г. $50 \%$ опрошенных сочли, что предпринимаемые администрацией Трампа меры по принуждению Ирана к переговорам для “улучшения ядерной сделки" (а не полного отказа от неё) могут оказаться продуктивными [Half think new Iran sanctions..., August 09, 2018]. В общественном мнении США укрепляется восприятие Ирана (его “экспансионистской политики” и ядерной программы) как значимой угрозы для Америки и её союзников, а Сирии - как частного случая воспроизведения и одновременно “подпитки” этой угрозы режимом Асада, который становится неотделим от "режима иранских мулл". Сирия, таким образом, вполне может определяться в рамках “новой стратегии” Трампа как поле ограниченного применения военной силы для противодействия, прежде всего, Ирану.

Среди предлагаемых различными “мозговыми центрами” в США обновлений нынешнего подхода Белого дома к проблеме Сирии-Ирана заметно преобладает восприятие этого конфликтного узла в вышеуказанном ключе (“Сирия для США частный случай проявления противостояния с Ираном"). Тем не менее появляются и аналитические работы, посвящённые обновлению сирийского аспекта стратегии США. Одна из наиболее, на наш взгляд, значимых работ - аналитический доклад под названием "10-градусное смещение в сирийской стратегии" (A 10-degree shift in Syria strategy), подготовленный на базе Брукингского института группой известных специалистов по вопросам безопасности и Ближнего Востока [Alaaldin, Fritz, Heydemann, Jones, O’Hanlon, 2018]. Выводы и рекомендации авторов доклада не только вполне, на наш взгляд, вписываются в общие постулаты “новой стратегии США по Сирии", но их можно рассматривать как детализацию данной стратегии ${ }^{1}$.

В том, что касается отношения США и, как подразумевается, Евросоюза к происходящему на территории Сирии, контролируемой Асадом и его партнёрами (Ираном и Россией), то один из принципиальных аспектов прописан в докладе так: “...США должны прилагать усилия с тем, чтобы наращивать разногласия внутри проасадовского альянса, содействовать возникновению условий, которые могли бы побуждать отдельных участников прорежимной коалиции прийти к выводу о том, что им будет намного лучше при смене руководства в Дамаске. Намеченные на 2021 г. выборы могли бы стать важным рубежом для такого транзита, если он не произойдёт раньше"2.

\section{Евросоюз - Сирия: как избежать гуманитарной катастрофы}

В отличие от США лидеры ведущих стран Евросоюза рассматривают сирийский конфликт как проблему отдельную, лишь частично связанную с Ираном. При этом в своих официальных оценках происходящего в Сирии Евросоюз сохраняет

\footnotetext{
${ }^{1}$ https://www.brookings.edu/wp-content/uploads/2018/09/FP_20180907_syria_strategy.pdf, pp. 6-9. 2 там же, стр. 11.
} 
акцент на приоритете “ценностных" и гуманитарных составляющих его подхода над “интересами” и геополитикой. С учетом особенностей и сложности процесса согласования и принятия решений на уровне ЕС в конечном счете принципиальная единая позиция стран-членов в меньшей степени подвержена корректировкам, чем это происходит в Соединённых Штатах. Особенно устойчива общеевропейская позиция в отношении внешних конфликтов, в частности, в Сирии и вокруг нее. На данный момент отношение стран ЕС к данной проблеме определяется принципами, одобренными Советом Евросоюза 3 апреля 2017 г. [Council adopts EU strategy on Syria, 2017]. Главные из них изложены в следующих шести пунктах:

1. Прилагать усилия для окончания войны в Сирии посредством подлинного политического транзита в соответствии с резолюцией СБ ООН 2254.

2. Обеспечить инклюзивный процесс перехода власти в Сирии согласно резолюции 2254 и Женевского коммюнике 2012 г. посредством оказания поддержки политической оппозиции для усиления её роли.

3. Спасать жизни людей, стремясь удовлетворять гуманитарные потребности наиболее уязвимой части сирийских граждан в стране, действуя своевременно, эффективно и в духе согласованных принципов.

4. Содействовать продвижению демократии, соблюдению прав человека и свободы слова посредством укрепления организаций гражданского общества в Сирии.

5. Содействовать привлечению к ответственности лиц за совершение военных преступлений с учётом продвижения процесса национального примирения.

6. Поддерживать жизнеспособность сирийского населения и общества в этой стране [The EU and the crisis in Syria, 2018].

Между тем в силу ряда причин ${ }^{1}$ с самого начала сирийского кризиса (в марте 2011 г.) ЕС как международно-политический фактор оказался на вторых ролях, уступив лидирующую позицию (в рамках Евро-Атлантики) Соединённым Штатам. Это проявлялось, в частности, в том, что на протяжении всего периода трагических потрясений в Сирии и по сей день Евросоюз не выступил ни с одной значимой инициативой, ограничиваясь участием в мероприятиях так называемой неформальной группы “Друзья Сирии” (около 70 государств), созданной в феврале 2012 г. президентом Франции Николя Саркози. Политическим приоритетом “Друзей Сирии” стала линия на поддержку умеренной оппозиции правительству Башара Асада (главным образом Сирийской свободной армии (ССА). И это при том что США, по мнению Марка Пьерини, эксперта европейского филиала Фонда Карнеги, “несколько раз радикально меняли свою политику в отношении Сирии" [Пьерини, 2017].

Изначально (с 2011 г.) основными рычагами воздействия на нараставшее гражданское противостояние в Сирии стали для европейцев два: а) занятие жёсткой политической позиции против правительства Башара Асада (и соответственно поддержка оппозиционных сил), повлекшее принятие санкционных мер против Дамаска $^{2}$ и б) предоставление гуманитарной помощи мирному населению (с этой целью

\footnotetext{
${ }_{1}^{1}$ См. подробнее: [Шумилин, 2018а].

2 Евросоюз ввёл запрет на импорт сирийской нефти и на инвестиции в экономику САР, а также заморозил активы Центробанка этой страны на территории ЕС. Эти санкции продлены до 1 июня 2019 г. См. [The EU and the crisis in Syria, 2018].

Современная Европа, 2018, №6
} 
ЕС провели две международные донорские конференции по Сирии в Брюсселе в апреле 2017 и 2018 гг). ${ }^{1}$

После разгрома в начале 2018 г. основных группировок "Исламского государства" в Сирии ведущие страны ЕС, особенно Великобритания, Франция и Германия, заметно активизировали свои военные и дипломатические усилия в контексте приближения постконфликтного урегулирования. При этом лидеры “евротройки” в своих заявлениях и действиях демонстрировали приверженность вышеизложенным шести принципам, акцентируя необходимость возобновления дипломатических процессов, обеспечивающих политический транзит в Сирии (его результатом должен стать уход Асада с президентского поста).

Так, лидеры “евротройки” резко негативно отреагировали на вышеупомянутое заявление Трампа в апреле 2018 г. о намерении вывести американские войска из Сирии. С их точки зрения, подобный шаг мог бы существенно ослабить военную поддержку группировкам курдов и сирийских повстанцев на севере и востоке страны и тем самым спровоцировать проасадовскую коалицию (Дамаск - Тегеран Москва) начать наступление с целью установить контроль над этими территориями. Французский президент Эммануэль Макрон утверждает, что в ходе визита в Вашингтон ему удалось убедить Дональда Трампа отказаться от планов вывода американских войск с сирийской территории [Syria air strikes: Macron says..., 2018]. К своим заслугам относит французский президент и тот факт, что Трамп согласился с предложенным европейцами умеренным вариантом ракетных ударов по объектам армии Асада в апреле 2018 г., отклонив более радикальные опции его собственных советников (последние якобы включали удары по объектам, контролируемым Россией и Ираном в Сирии) [Syria air strikes: Macron says..., 2018]. В том же духе пытались влиять на американского президента главы Великобритании и Германии, которые не только впервые присоединились к американской акции возмездия против Асада (к ракетным ударам), но и пообещали увеличить собственный вклад на содержание войск международной коалиции против ИГИЛ, задействованных на северо-востоке Сирии. Более того, в своей речи 26 апреля 2018 г. в Лондоне в ходе Международной конференции по борьбе с финансированием ИГ и “Аль-Каиды" Макрон провозгласил создание, по его словам, “Парижской повестки” и “Парижской коалиции" в рамках глобальной коалиции по борьбе с ИГИЛ для выявления и ликвидации всех самых современных способов финансовых транзакций в пользу террористических группировок [President seeks global coalition against terrorism funding].

Подобные шаги можно расценивать как стремление европейцев (в данном случае президента Макрона) повысить уровень координации в ЕС в вопросах борьбы с терроризмом в целом и применительно к ситуации противоборства с ИГИЛ в Сирии в частности. О намерении европейцев усилить свою роль на сирийском направлении свидетельствует ряд шагов со стороны руководства Германии: так, канцлер Ангела Меркель пытается преодолеть сопротивление оппозиции в Бундестаге по вопросу возможного развертывания германских подразделений на территории Сирии [Germany says in talks about possible military role in Syria, 2018], a Урсула фон дер Ляйен, министр обороны Германии, подтвердила готовность своей страны рас-

${ }^{1}$ С 2011 по 2018 г. на обеспечение первичных потребностей мирного населения в местах боевых действий и в лагерях беженцев Евросоюз израсходовал свыше 11 млрд евро. См. там же. А также см. Вторая Брюссельская конференция "Поддержка будущего Сирии и региона", 24-25 апреля 2018 - https://eeas.europa.eu/headquarters/headquarters-homepage_ru/42954/

Современная Европа, 2018, №6 
смотреть вопрос о создании первой постоянной базы немецких войск на Ближнем Востоке [Siebold, 2018]. Об этом она заявила в середине сентября 2018 г., находясь с рабочим визитом в Иордании, куда Германия переводит порядка 300 своих военнослужащих с турецкой авиабазы Инджерлик. Предполагается, что германские военнослужащие в Сирии займутся тренировкой подразделений курдов (включая и Пешмергу в Сирии и Ираке) и Сирийских демократических сил (умеренных оппозиционных Асаду группировок). Приверженность руководства Германии и Франции принципиальным установкам ЕС в отношении урегулирования сирийского конфликта (ставка на переговорный процесс в Женеве с участием оппозиционных Асаду сил и оказание гуманитарной помощи мирному населению) стала причиной отклонения лидерами этих двух стран недавней российской инициативы по возвращению и обустройству сирийских беженцев. Казалось бы, Москва предлагала Парижу и Берлину конструктивные варианты привлечения последних к созданию надлежащих условий для приема беженцев на территории Сирии, что могло снизить давление этой проблемы на политические круги Германии и Франции. Те, однако, заявили о своей готовности заняться обустройством беженцев после достижения устойчивого политического урегулирования в Сирии с участием оппозиционных сил [Шумилин, 2018b]. То есть после ухода Б. Асада с поста президента.

Другим проявлением превалирования гуманитарных (“ценностных") озабоченностей европейцев в подходе к сирийскому кризису стала концентрация правительств ведущих стран ЕС на проблеме эвакуации членов организации "Белые каски" и членов их семей (порядка 800 человек) из юго-западных районов Сирии в июле 2018 г. - в период наступательных операций армии Асада и его союзников на анклавы оппозиции там [Germany: FMs Hunt and Mass praise rescue of Syrian White Helmets, 2018]. Заметим, что упомянутая организация воспринимается европейским истеблишментом как гуманитарная, оказывающая первую помощь мирному населению во время боевых действий, за что ей были присуждены несколько международных (в основном европейских) наград, включая так называемую альтернативную нобелевскую премию - The Right Livelihood Award (за 2016 г.). Созданная в 2014 г. отставным британским офицером Джеймсом Ле Межурера из разрозненных отрядов сирийских волонтёров организация "Белые каски" в основном финансировалась из правительственных источников ведущих стран Евросоюза (поначалу только Великобритании) и американской USAID. Власти ряда стран EC её нередко представляют как символ “мирной гуманитарной интервенции" Евросоюза во внутрисирийский конфликт, хотя при этом иногда и не отрицают связь активистов “Белых касок" с радикальными группировками, борющимися против правительства Башара Асада [Блейкер, Барановская, 2018].

С приходом в Белый дом команда Д. Трампа заметно сместила акценты в восприятии сирийского конфликта по сравнению с администрацией Б. Обамы. Если последняя стремилась активно вовлекаться в процесс поиска урегулирования конфликта дипломатическим путем на основе выработанных в Женеве принципов, то нынешняя команда в Белом доме длительное время воздерживалась от погружения в переговорные процессы, полагая, что проблему можно решить путем сделки (договоренности) между Д. Трампом и В. Путиным. Окружение Трампа явно воспринимает ситуацию в Сирии и постконфликтное урегулирование как проблему вто- 
ричную по сравнению с приоритетной задачей - “противостоянием угрозе усиления военной мощи Ирана и его экспансии в регионе". Иными словами, “интересы” и геополитические расчёты оказывают определяющее влияние на формирование политики Трампа по Сирии. Во многом иной подход демонстрируют в этом вопросе ведущие страны ЕС - Франция, Германия, Великобритания. Он основан на приоритете усилий по поиску политического урегулирования в Сирии посредством дипломатических переговоров на основе Женевских документов и принципов, предполагающих смену власти в Дамаске. Европейцы склонны отделять "проблему Сирии” от “проблемы Ирана". При этом они намерены поддерживать военный потенциал противостоящих Асаду группировок, контролирующих северо-восток Сирии. Срыв планировавшейся Трампом (на саммите в Хельсинки) сделки с Путиным по Ирану побудил Белый дом обновить сирийскую стратегию. Отныне она предполагает активизацию силовой составляющей с целью воздействия на правительство Асада и Иран, смещение Асада путём как закулисных сделок, так и создания "альтернативы для сирийцев” посредством обеспечения ускоренной нормализации жизни в районах вне контроля Асада, а также возможную активизацию переговорных процессов. В результате основные параметры обновленной стратегии США по Сирии во многом совпадают с европейским видением проблемы.

Список литературы

Блейкер К., Барановская М. (2018) Сирийские “Белые каски": герои-спасатели со спорными связями / DW. 25.07.2018. URL: https://www.dw.com/ru/сирийские-белые-каски-герои-спасатели-соспорными-связями/a-44809300.

Война в Сирии: кто контролирует Идлиб (2018) // BBC News. 10 сентября 2018. URL: https://www.bbc.com/russian/features-45476176.

Лавров считает уход Ирана из Сирии нереалистичным (2018) // РИА Новости. 04.07.2018. URL: https://ria.ru/syria/20180704/1523924337.html.

Пьерини М. Есть ли у ЕС роль в сирийском конфликте (2017). Московский Центр Карнеги. 16 февраля 2017. URL: https://carnegie.ru/2017/02/16/ru-pub-68006.

Шумилин А. (2018a) Евросоюз: подход к сирийской проблеме (2018) / Научно-аналитический вестник ИЕ РАН, №2, с. 201-209.

Шумилин А. (2018b) Сирийское урегулирование: взгляд из Европы (2018) / Научноаналитический вестник ИЕ РАН, №4, с. 165-172.

References

Blejker K., Baranovskaya M. (2018) Sirijskie belye kaski geroi-spasateli so spornymi svyazyami // DW. 25.07.2018. URL: https://www.dw.com/ru/сирийские-белые-каски-герои-спасатели-со-спорнымисвязями $/$ - 44809300 .

Lavrov schitaet uhod Irana iz Sirii nerealistichnym (2018) // RIA Novosti. 04.07.2018. URL: https://ria.ru/syria/20180704/1523924337.html.

Perini M. Est li u ES rol v sirijskom konflikte (2017). Moskovskij centr Karnegi. 16 fevralya 2017. URL: https://carnegie.ru/2017/02/16/ru-pub-68006.

Shumilin A. Evrosoyuz: podhod k sirijskoj probleme (2018) // Nauchno-analiticheskij vestnik IE RAN, №2, c. 201-209.

Shumilin A. Sirijskoe uregulirovanie: vzglyad iz Evropy (2018) // Nauchno-analiticheskij-vestnik IE $R A N$, №4, c. 165-172.

Vojna v Sirii: kto kontroliruet Idlib (2018) // BBC News. 10 sentyabrya 2018. URL: https://www.bbc.com/russian/features-45476176.

Alaaldin R., Fritz J., Heydemann S., Jones B., O’Hanlon M. (2018) A 10-degree shift in Syria strategy / The Brookings Institution, September 2018. URL: https://www.brookings.edu/research/a-10-degree-shift-insyriastrategy/?utm_campaign=Foreign $\% 20$ Policy\&utm_source=hs_email\&utm_medium=email\&utm_ content $=65936650$.

Council adopts EU strategy on Syria (2017) // European Council. 03/04/2017. URL: http://www.consilium.europa.eu/en/press/press-releases/2017/04/03/fac-conclusions-syria/?utm_source= dsmsauto\&utm_medium=email\&utm_campaign=Council+adopts+EU+strategy+on+Syria

Современная Европа, 2018, №6 
DeYoung K., Harris S. (2018) Trump instructs military to begin planning for withdrawal from Syria /The Washington Post. April 4. 2018. URL: https://www.washingtonpost.com/world/national-security/trumpinstructs-military-to-begin-planning-for-withdrawal-from-syria/2018/04/04/1039f420-3811-11e8-8fd249fe3c675a89_story.html?utm_term=.ffea829ce585.

DeYoung K. (2018) Trump agrees to an indefinite military effort and new diplomatic push in Syria, U.S. officials say / The Washington Post. September 6, 2018. URL:

https://www.washingtonpost.com/world/national-security/in-a-shift-trump-approves-an-indefinite-militaryand-diplomatic-effort-in-syria-us-officials-say/2018/09/06/0351ab54-b20f-11e8-9a6a-

565d92a3585d_story.html?noredirect=on\&utm_term=.3c7a66fffa24.

Garden J. (2018) A New Poll Shows the Public Is Overwhelmingly Opposed to Endless US Military Interventions / The Nation. January 9, 2018. URL: https://www.thenation.com/article/new-poll-shows-publicoverwhelmingly-opposed-to-endless-us-military-interventions/.

Germany says in talks about possible military role in Syria (2018)/ Reuters. September 10, 2018. URL: https://www.reuters.com/article/us-mideast-crisis-syria-germany/germany-says-in-talks-about-possiblemilitary-role-in-syria-idUSKCN1LQ124.

Germany: FMs Hunt and Mass praise rescue of Syrian White Helmets (2018) / Newstube. 5 декабря 2018 - https://www.newstube.ru/media/germany-fms-hunt-and-mass-praise-rescue-of-syrian-white-helmets.

Half think new Iran sanctions will be effective in renegotiating nuclear deal (2018) / Rasmussen Reports. August 09, 2018. URL: http://www.rasmussenreports.com/public_content/politics/current_events/iran/ half_think_new_iran_sanctions_will_be_effective_in_renegotiating_nuclear_deal.

President seeks global coalition against terrorism funding / International conference on combating the financing of Daesh and al-Qaeda - Speech by M. Emmanuel Macron, President of the Republic // Embassy of France in London. URL: https://uk.ambafrance.org/President-seeks-global-coalition-against-terrorismfunding

Reinhart R. Snapshot: Half of Americans approve of strikes on Syria (2018) / Gallup. April 24, 2018. URL: https://news.gallup.com/poll/232997/snapshot-half-americans-approve-strikes-syria.aspx.

Siebold S. (2018) Germany committed over long-term to help Iraq rebuild: defense minister / Reuters,. September 16, 2018. URL: https://www.reuters.com/article/us-iraq-germany/germany-committed-over-longterm-to-help-iraq-rebuild-defense-minister-idUSKCN1LW0GQ.

Syria air strikes: Macron says he convinced Trump not to pull out troops (2018) / BBC News. 16/04/2018. URL: http://www.bbc.com/news/world-middle-east-43778831.

The EU and the crisis in Syria (2018) // EEAS. 16/04/2018. URL: https://eeas.europa.eu/headquarters/ headquartershomepage_en/22664/The\%20EU\%20and\%20the\%20crisis\%20in\%20Syria.

Watkins E. (2018) Trump blames Putin, Obama for 'Animal Assad', tweets 'big price' after reports of Syrian chemical attack / CNN. April 9, 2018. URL: https://edition.cnn.com/2018/04/08/politics/donaldtrump-syria-assad/index.html.

Williams D. (2018) Trump adviser Bolton says Russia 'stuck' in Syria, Iran must leave / Reuters. August 22, 2018. URL: https://www.reuters.com/article/us-mideast-crisis-syria-usa-russia-inter/trump-adviserbolton-says-russia-stuck-in-syria-iran-must-leave-idUSKCN1L709R.

\section{Syria after ISIS: the specifics of the USA\&EU's approaches}

Authors: Shumilin A., Doctor of Political Sciences, Chief Research Fellow at the Department of European security at the Institute of Europe of RAS. Address: 11-3, Mokhovaya Str., Moscow, Russia, 125009. E-mail: mideast@bk.ru

Shumilina I., Senior Research Fellow at the Center for social and political researches at the Institute for the USA\&Canada studies of RAS. Address: 2/3, Khlebniy lane, Moscow, Russia, 121069. E-mail: innashu@mail.ru

Abstract. In 2018 the Donald Trump's team has been obviously updating its strategy for the Syrian crisis: from the intent, proclaimed in April, to withdraw the American troops from Syria up to the statement made in August on the US readiness to put stakes on the military force as well as on diplomacy to achieve the new prevailing task - to push out Iran from this Arab country. The Washington's attempt to compel Moscow to join its anti-Iranian approach eventually failed. Neither the EU countries are ready to share in full Trump's anti-Iranian strategy in Syria. The authors texamines the specifics of the US-EU relationship on the Syrian issue.

Key words: USA, European Union, Syria, Iran, Russia, compromise, jihadists, ISIS, Donald Trump, Emmanuel Macron, Angela Merkel, Vladimir Putin.

DOI: http://dx.doi.org/10.15211/soveurope620187381 